\title{
USING SELF-GENERATED PRIORS IN DIVISION LEADS TO BIASED CONSUMER JUDGMENTS
}

Ignazio Ziano (Ignazio.ziano@grenoble-em.com) is Assistant Professor of Marketing at Grenoble Ecole de Management, 12 Rue Pierre Semard, 38000 Grenoble (France).

Daniel Villanova (dvillanova@walton.uark.edu) is Assistant Professor of Marketing at Sam M. Walton College of Business, University of Arkansas, 220 North McIlroy Avenue, Fayetteville, AR 72701, USA.

\begin{abstract}
Consumers often have to make divisions to evaluate attributes. In six experiments (total $\mathrm{N}=$ 3296, four preregistered), this research shows that consumers may rely on their prior for the attribute to generate an estimate rather than divide following a normative procedure. That is, consumers will recruit typical values of the attribute from memory and use them when dividing. This process influences consumers' judgments. When the actual attribute value is above the attribute prior, it tends to be underestimated, and when it is below the attribute prior, it tends to be overestimated. When the attribute is a product attribute (such the milesper-gallon a car can drive), this decreases its attractiveness. When the attribute is a companywide attribute (such as median wage), this intuitive approach results in corresponding changes in company evaluations, willingness-to-pay, and product choice. The authors discuss theoretical implications for consumers' numerical cognition, anchoring and adjustment, and perceptions of income inequality. Practical implications for the communication and disclosure of product attribute information and income inequality for managers and policymakers are also discussed.
\end{abstract}

Keywords: income inequality, CEO, median salary, numerical cognition, division 
Consumers sometimes face incomplete information and have to fill in the blanks for themselves. One such case is when they have to calculate an answer from quantitative information, such as arriving at a quotient by dividing two numbers in order to evaluate an important product attribute. For instance, in order to estimate how fuel-efficient a car is, consumers might have to divide the miles they drove by the gallons of gas they consumed. We show that often consumers do not divide accurately. More importantly, we shed light on the process used by consumers- they adjust around their existing prior estimate (i.e., what is seen as typical for the target attribute). This leads to estimates that on average fall between their prior for the attribute quotient and the correct quotient that would result if consumers had actually divided accurately.

This process results in the overestimation of attribute values when the actual value is below the typical prior $^{1}$ (i.e., the prior inappropriately pulls the average estimate upward) and in the underestimation of attribute values when the actual value is above the typical prior (i.e., the prior inappropriately pulls the average estimate downward). In turn, this leads consumers to biased attribute evaluations (compared to their evaluations when the attribute quotient is

\footnotetext{
${ }^{1}$ With "typical prior", we mean the value of the attribute that consumers store in memory as "typical". For instance, in Study 3, we discovered that participants consider a "typical salary" in a certain industrial sector to be around $\$ 55,000$ per year, and in Study $1 \mathrm{~b}$, that they considered that a "typical sedan made by a Japanese manufacturer" would have a fuel-efficiency of 25.5 miles-per-gallon.
} 
given) and distorts their willingness-to-pay (WTP) for a product as well as their product choice.

This process is at play in several domains. Consumers may have to perform divisions when they are evaluating a product attribute such as MPG, but they also engage in calculative processes for a host of other judgments, including forming impressions of firms based on employee and CEO salaries (Benedetti and Chen 2018; Ziano, Lembregts, and Pandelaere 2019). Ironically, the over- and under-estimation effects unfairly reward companies that pay below-typical salaries and penalize companies that pay above-typical salaries.

These findings contribute to our understanding of how people respond to numerical information, an important area of research given the ubiquity of numerical stimuli in the marketplace (Landy, Guay, and Marghetis, 2017; Landy, Silbert, and Goldin, 2013), with potential application in a wide range of fields, from product attribute evaluation to the impact of income inequality on consumers. Previous research has studied factors affecting consumers' propensities to calculate (Biswas et al. 2013) and some of the tendencies involved when using normative calculation algorithms (Villanova and Bagchi 2020), but there remains room for insights into intuitive approaches, which we study in this research.

Further, we contribute to the research on anchoring. While there is a large literature that shows the effects of anchoring on a variety of consumer-relevant psychological processes (Furnham and Boo 2011), these anchors are provided by the experimenter, either directly (e.g., Morwitz, Greenleaf, and Johnson 1998) or by inducing participants into coming up with “self-generated anchors" (Epley and Gilovich 2006; Fox and Rottenstreich 2003). In our research, we show that consumers making estimates often rely on natural anchors that they spontaneously generate, based on their prior experience with the attribute. 
The present research also contributes to the understanding of income inequality by laypeople, and for its consequences in terms of consumer behavior and perceptions of the firm. Given that division and numerical data of this type is implicated in the judgments of within-company income inequality (Kiatpongsan and Norton 2014; Ziano, Pandelaere, and Lembregts 2019), the present work contributes to this line of research, clarifying how income inequality data is perceived and evaluated and its consequences for consumer behavior.

We discuss these theoretical implications in greater detail in the General Discussion. We also present managerial implications for the communication of attributes and disclosure of income inequality data with different perspectives for the policymaker and the marketing manager. Next, we turn to our conceptual development.

\section{CONSUMER CALCULATIONS}

Calculation is not always easy, and humans are prone to errors (Ashcraft 1992). Often, consumers respond to calculation problems by taking mental shortcuts (Hitch 1978). Rather than formally calculating solutions with the correct algorithms, consumers sometimes allow certain numbers to play an outsize role, in a process called anchoring and adjustment (Epley and Gilovich 2006; Tversky and Kahneman 1974b). For example, when unit prices are difficult to precisely calculate, the order of presenting price and quantity information affects consumer evaluations of package offers (Bagchi and Davis 2012).

Research in partitioned pricing shows that anchoring and adjustment affects how consumers evaluate prices and can even result in neglecting surcharges completely (Morwitz et al. 1998). In fact, Morwitz et al. (1998) offer several observations pertinent to the present research. They note that there are three general processing strategies available to consumers 
faced with having to perform a calculation: 1) retrieving the algorithm to calculate the answer; 2) using an alternative strategy, particularly anchoring and adjustment, to process the available information; or 3) ignoring some of the information completely. Their focus, like ours, is on the second option, the alternative strategies.

We focus on how consumers respond to division problems. Division problems are particularly intriguing from a marketing perspective as ratios are used in many consumer assessments, including those of gambles (de Langhe and Puntoni 2015), discounts (Bartels 2006), and value (Capon and Kuhn 1982; Zeithaml 1988). People also commonly make errors when dividing (Parker and Leinhardt 1995). Recent research has probed how individuals approach dividing for evaluating package offers and found that they are influenced by an intuitive model of division that encourages dividing larger by smaller numbers (Villanova and Bagchi 2020). However, an alternative to actual division is also available to consumers faced with a division problem.

We suggest that when consumers are faced with the need to compute a quotient, rather than engaging in actual division, many may use an alternative strategy. The strategy we focus on is one where consumers attempt to use their prior estimate of what is a typical value for the attribute. This process has a resemblance with Bayesian inference where individuals combine a prior with new data to form a posterior estimate (Fennell and Baddeley 2012; Landy et al. 2017). But one distinction is that the "new data" in the situations we study are not readily combinable with the prior and would require actual division to prepare them, after which point using the prior would be superfluous. Thus, relying on a prior for what is typical comes at the neglect of the pertinent information that should guide consumers' evaluations.

For example, consider a CEO that makes $\$ 6$ million, 400 times the average employee. How much does the average employee make? Correct division would yield $\$ 15,000$. But an 
individual who declines to calculate and thinks a typical salary is somewhere around $\$ 50,000$ (in line with income statistics in the United States) would rely on that prior (or near it) and estimate a salary higher than the true quotient. Now consider a similar situation in which the CEO salary is $\$ 42$ million. How much does the average employee make? Correct division would yield $\$ 105,000$, but relying on the prior would lead to estimating a salary lower than the true quotient.

Similarly, the average fuel efficiency of a sedan car in the USA in 2019 was 30.5 miles-per-gallon (United States Environmental Protection Agency 2020). Consumers may be presented with independent car reviews where an independent magazine takes the car out for a ride of a pre-established length (e.g., 75 miles). After that, gas consumption (in gallons for a US audience) is ascertained by the reviewer. Again, here consumers must make a division. If the result would fall on the lower end of the range (for instance, $12 \mathrm{mpg}$ ), consumers will likely overestimate the car's fuel-efficiency and form a better evaluation of the car compared to the actual fuel-efficiency. If the result would fall on the higher end of the range (for instance, $60 \mathrm{mpg}$ ), consumers will likely underestimate the car's fuel-efficiency and form a worse evaluation of the car compared to its actual fuel-efficiency.

Note that not all consumers will rely on their prior to calculate the quotient. A significant portion may make an accurate division, which will result in an accurate quotient. This process, then, should be expected to result, on average, in the overestimation of attribute values when the actual value is below the typical prior (i.e., the prior inappropriately pulls the average estimate upward from the true quotient) and in the underestimation of attribute values when the actual value is above the typical prior (i.e., the prior inappropriately pulls the average estimate downward from the true quotient). This leads us to formulate $\mathrm{H} 1$ and $\mathrm{H} 2$ : 
H1: Estimated quotients will be overestimated when the true quotient is below the typical value, and underestimated when the true quotient is above the typical value

$\mathrm{H} 2$ : Estimated quotients will be a function of the typical attribute value consumers store in memory

\section{CONSUMERS’ PRIORS AND EVALUATIONS}

Our empirical investigation primarily focuses on judgments stemming from information regarding income inequality, both for the practical importance of this context and for the clear theoretical test it provides. In the United States, the Dodd-Frank Act of 2010 introduced a transparency requirement for public companies: CEO total compensation (including stock options), median employee compensation, and the ratio between CEO total compensation and median employee compensation are now described in quarterly reports (Securities and Exchange Commission 2017). Similar measures have recently been adopted in other countries, such as the United Kingdom (Deloitte 2018), and have been proposed in Switzerland (Hooper 2013). Seemingly every quarter, news media publish a slew of articles focusing on CEO compensation and the ratio to the median employee (Campbell 2019; Mishel and Schiedler 2017; Rushe 2019).

This current tendency may be misleading because the median salary is the global median salary without taking into account purchasing power. For instance, the McDonald's median employee makes about $\$ 7,000$ a year, but is based in Poland, which has a lower cost of living than the USA, where the company and the CEO are based (Greenberg 2019). Despite this, employee pay, rather than the CEO pay or the pay ratio, drives fairness and 
inequality judgments (Ziano, Pandelaere, and Lembregts 2019). Interestingly, when these articles focus on a single company, they frequently fail to mention median employee pay (e.g., Scheyder 2017), leaving the task of calculating it to the reader. Thus, current practice suffers further as consumers are forced to derive employee pay themselves.

This creates an opportunity for relying on priors to bias consumer perceptions of pay fairness. When consumers have only CEO pay and ratio, they are faced with a division problem to estimate employee pay by either marshaling the correct division algorithm or using their priors. Given the under- and over-estimation effects hypothesized in H1, this suggests that priors will unfairly reward companies that pay below-typical salaries and penalize companies that pay above-typical salaries. Formally:

H3: Pay fairness will be over-evaluated (compared to evaluations when the attribute quotient is given) when the true quotient is below the typical value, and underevaluated (compared to evaluations when the attribute quotient is given) when the true quotient is above the typical value

We expect these pay fairness evaluations to have further downstream consequences. From a human resources standpoint, perceptions of employee well-being and interest in becoming employed by the firm are expected to be affected by perceived pay fairness. Further, as companies are often treated as people (Kervyn, Fiske, and Malone 2012), perceptions of pay fairness can also impact the overall image of the firm.

From a consumer behavior perspective, WTP and product choice are expected to be affected by perceived pay fairness. In general, companies that pay a fair salary, and behave otherwise ethically are perceived more positively (Trudel and Cotte 2009). Following equity 
theory (Adams and Freedman 1976), consumers may wish to compensate companies that treat their employees better (Cotte and Trudel 2009; Mohan et al. 2018).

Thus:

H4: Perceptions of employee well-being and employment interest will be mediated by perceived pay fairness, penalizing companies with higher-than-typical salaries and rewarding companies with lower-than-typical salaries

H5: WTP and product choice will be mediated by perceived pay fairness, penalizing companies with higher-than-typical salaries and rewarding companies with lowerthan-typical salaries

\section{STUDY OVERVIEW}

We test our hypotheses in six studies (summarized in Table 1). Study 1A shows that consumers under-evaluate an attribute (pay fairness) when the target quotient is above their prior. Study 1B shows that consumers over-evaluate an attribute (fuel efficiency) when the target quotient is below their prior. Together, these support H3. Study 2 shows both of these effects simultaneously and highlights the importance of under- and over-estimates, supporting $\mathrm{H} 1$ and $\mathrm{H} 2$. Study 3 provides direct evidence for our proposed process by illustrating the use of the prior information available in memory. Studies 4 and 5 present results with direct practical relevance by showing that reliance on a prior not only biases fairness perceptions but also has consequences for hiring-relevant impressions about the firm, willingness-to-pay, and product choice, supporting H4 and H5. For each study, supplemental 
analyses are presented in the Web Appendix. Complete data and analyses are available at https://osf.io/v64w5/?view_only=b97f3ca6b46744609a85f30370483479. 
TABLE 1

STUDY OVERVIEW

\begin{tabular}{|c|c|c|c|}
\hline Study & $\mathrm{N}$ & Attribute level & Main result \\
\hline Study $1 \mathrm{~A}$ & 299 & High & $\begin{array}{l}\text { Individuals consider a salary less fair when they have to make a } \\
\text { division themselves (vs. having the quotient presented) }\end{array}$ \\
\hline Study 1B & 401 & Low & $\begin{array}{l}\text { Individuals consider a car more fuel-efficient when they have to } \\
\text { make a division themselves (vs. having the quotient presented) }\end{array}$ \\
\hline Study 2 & 610 & High and low & $\begin{array}{l}\text { Individuals over- and under-estimate salaries when they have to } \\
\text { make divisions themselves, which affects fairness judgments }\end{array}$ \\
\hline Study 3 & 584 & High and low & Priors influence consumers' estimates, which affects judgments \\
\hline Study 4 & 602 & High and low & $\begin{array}{l}\text { Salary misestimation affects company perceptions and has human } \\
\text { resources consequences }\end{array}$ \\
\hline Study 5 & 800 & Low & Salary misestimation affects willingness-to-pay and product choice \\
\hline
\end{tabular}

Note. The attribute level is considered high or low compared to both typical level of the attribute in the marketplace (e.g., study 1b) and to typical priors that consumers have in mind (e.g., Study 3). 


\section{STUDY 1A - UNDER-EVALUATION OF A HIGH QUOTIENT: SALARY FAIRNESS}

In Study 1A, we explore how the perceived fairness of compensation compares between the common situation of estimating employee pay as a quotient and the alternative situation of having complete information.

Method

We recruited 299 participants on MTurk for this study (156 males, 143 females; 296 from the US, 2 from the UK, 1 from another country; $M_{\mathrm{age}}=36.59 ; S D_{a g e}=11.59$ ). Participants were randomly assigned to one of two information conditions: incomplete or complete. In the incomplete information condition, they were shown the following scenario (in the complete information condition, they were also shown the information in brackets):

\footnotetext{
At Destelbergen, a technology company located in Dallas, TX, with about 3000 employees total, the CEO makes about $\$ 20$ million a year. The CEO pay is 200 (two hundred) times higher than the median employee pay.

[The median employee pay is $\$ 100$ thousand a year].
}

Note that in both conditions, median employee pay is $\$ 100,000$ per year, but while those in the incomplete information condition would need to estimate this quotient, those in the complete information condition had access to the actual quotient. Because US median individual and household incomes were between about $\$ 33,000$ and $\$ 63,000$ (US Census Bureau 2018), we expected this salary to be "high" and thus subject to an underestimation 
effect, since most people have a good idea of what a "normal salary" is (Ziano et al. 2019). That is, we expected fairness perceptions to be lower when individuals estimate employee pay as a quotient compared to when they have complete information.

All participants were asked two questions on 7-point Likert-type scales anchored at 1 = Not at all, 7 = Very much: “Are employees' pays fair?”; “Are employees' pays just?”). The two questions showed high reliability $(\alpha=.97)$ and were thus averaged into an index of employee pay fairness. Participants were also asked about CEO pay fairness $(\alpha=.91)$, the results of which we report in the Web Appendix.

Results

Participants rated employee pay as less fair in the incomplete information condition $(M=3.05, \mathrm{SD}=1.62)$ compared to the complete information condition $(M=4.57, \mathrm{SD}=$ $1.55 ; t(297)=-8.27, p<.001, d=0.96)$. In line with our prediction, consumers underevaluated pay fairness when they had to estimate median pay versus when they had the full information.

Discussion

In this study, we showed that consumers consider the same salaries less fair when they have to calculate it compared to when they are presented with it. This suggests that people are under-evaluating salaries when salaries are above what is typical. Next, we investigate how consumers make divisions when presented with a different attribute (fuel-efficiency), below what is typical. 
In Study 1B, we explore how the perceived fuel efficiency of a car compares between the situation of estimating efficiency as a quotient and the alternative situation of having complete information.

This study was preregistered at http://aspredicted.org/blind.php? $\mathrm{x}=\mathrm{rw} 8 \mathrm{mk} 4$.

\section{Method}

We recruited 401 participants from MTurk. Six participants answered "Yes" to the question "Have you ever had a fatal heart attack?" (Yes/No answer) and were excluded from analyses, as we preregistered, leaving a final sample of 395 MTurk participants (211 males, 181 females, 2 other, 1 preferred not to disclose, $\left.M_{\text {age }}=37.4\right)$.

Participants completed demographics and the attention check at the start of the survey. Then, participants were randomly assigned to one of two information conditions: incomplete or complete. In the incomplete information condition, they were shown the following scenario (in the complete information condition, they were also shown the information in brackets):

Car X is a sedan made by a Japanese manufacturer.

A sedan is a car having a closed body and a closed trunk separated from the part in which the driver and passengers sit.

In a test run in real driving conditions, Car X used 6 gallons of gas in 75 miles.

[This amounts to 12.5 miles per gallon (mpg).] 
Note that in both conditions, fuel efficiency is $12.5 \mathrm{MPG}$, but while those in the incomplete information condition would need to estimate this quotient, those in the complete information condition had access to the actual quotient. We expected an over-evaluation effect because we expected this fuel efficiency to be "low" (the average US MPG is 30.5 [US Environmental Protection Agency 2020], and in a separate pretest the perceived average MPG of a "typical sedan made by a Japanese manufacturer" was 25.5). That is, we expected fuel efficiency perceptions to be higher when individuals estimate efficiency as a quotient compared to when they have complete information. Participants reported their judgment of fuel-efficiency ("How fuel-efficient is Car X?" 1 = Not at all, 7 = Very much). We collected additional measures, which are analysed and discussed in the Web Appendix.

Results

Participants rated Car X as more efficient in the incomplete information condition $(M$ $=2.82, \mathrm{SD}=1.94)$ compared to the complete information condition $(M=2.13, \mathrm{SD}=1.65$; Welch's $t(383.95)=-3.81, p<.001, d=0.38)$. In line with our prediction, consumers overevaluated the car's fuel efficiency when they had to estimate MPG versus compared with when they had the full information.

\section{Discussion}

This study shows that when consumers are presented with a below-typical attribute, and they have to calculate it, they tend to over-evaluate the attribute. This study extends our findings to another product (car) and another attribute (mpg), and complements the results of Study 1A, which focused on an attribute that was above-typical (see Figure 1). Next, we 
deepen our investigation into the psychological process underpinning consumers' approaches to these division problems.

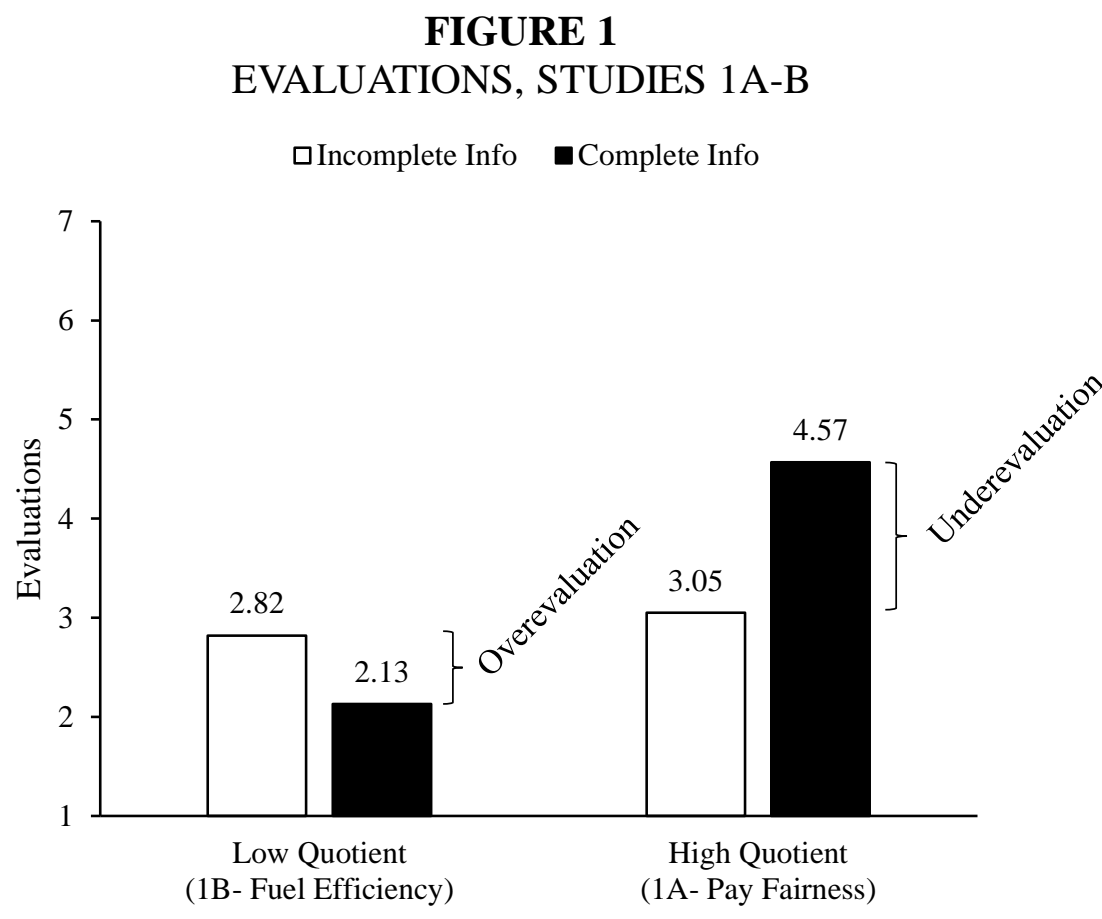

\section{STUDY 2 - UNDER- AND OVER-EVALUATION}

The objective of this study is to show both of the under- and over-evaluation effects on salary fairness in the same study, with concomitant under- and over-estimation of the quotients. This study was preregistered at http://aspredicted.org/blind.php? $\mathrm{x}=\mathrm{hg} 9 \mathrm{pm} 2$.

Methods

We recruited 610 participants from Amazon Mechanical Turk (268 males, 342 females, $\left.M_{\text {age }}=38.54, S D_{\text {age }}=11.57\right)$. Participants were randomly assigned to one of four 
conditions in a 2 (information: incomplete, complete) x 2 (quotient: low, high) design. Participants in the low quotient condition were shown the following scenario (in the complete information condition, they were also shown the information in square brackets; participants in the high quotient condition were shown the numerical information contained in the curly brackets):

Petersons, an Internet e-book company based in Kansas City (MO), has about 2,500 employees and a revenue of about $\$ 350$ million per year. CEO pay at Peterson is around $\$ 1.1\{10.1\}$ million per year. [Median employee pay at Petersons is $\$ 11\{101\}$ thousand a year.] CEO pay is 100 times higher than median employee pay.

Participants were then asked to rate employee salary fairness on a single item anchored at 1 (not at all) and 7 (very much). On the next screen, participants were asked to report the median employee salaries, on a slider anchored at $\$ 0$ and $\$ 120,000$. We used these estimates to compute their deviations from the true average employee salaries in their respective conditions. They also reported estimated median employee salaries on a 22-point scale with each point corresponding to a $\$ 5,000$ interval (e.g., $1=\$ 0$ to $\$ 5,000 ; 2=\$ 5,001$ to $\$ 10,000 \ldots 22=\$ 120,001$ or more). The Likert estimation results are provided in the Web Appendix and provide converging support to the slider estimation. We also collected other measures for this study, which we report and analyze in full in the Web Appendix. 
Results

Fairness. A two-way ANOVA with information and quotient as factors found a significant effect of Quotient $\left(F(1,606)=137.99, p<.001, \eta^{2}=.171\right)$, such that fairness was perceived as higher for the high quotient $(M=2.33, \mathrm{SD}=1.50)$ than for the low quotient $(M$ $=3.84, \mathrm{SD}=1.77)$. The main effect of Information was non-significant $(F(1,606)=1.10, p$ $\left.=.295, \eta^{2}=.001\right)$. Importantly, there was also a significant information $\mathrm{x}$ quotient interaction $\left(F(1,606)=60.65, p<.001, \eta^{2}=.075\right)$.

Tukey-corrected post-hoc tests showed that in the high quotient condition, participants rated employee pay as less fair in the incomplete information condition $(M=3.40, \mathrm{SD}=$ 1.79) compared to the complete information condition $(M=4.25, \mathrm{SD}=1.66 ; t(606)=4.73, p$ $<.001, d=0.50)$. In line with our prediction, consumers under-evaluated pay fairness. However, in the low quotient condition, participants rated employee pay as more fair in the incomplete information condition $(M=2.90, \mathrm{SD}=1.54)$ compared to the complete information condition $(M=1.78, \mathrm{SD}=1.24 ; t(606)=-6.29, p<.001, d=0.80)$. In line with our prediction, consumers over-evaluated pay fairness (see Figure 2).

Estimates. A two-way ANOVA with information and quotient as factors found a significant effect of Quotient $\left(F(1,606)=496.31, p<.001, \eta^{2}=.43\right)$, such that estimates were higher for the high quotient condition $(M=\$ 79,353.14, \mathrm{SD}=\$ 32,205.07)$ than for the low quotient condition $(M=\$ 26,794.67, \mathrm{SD}=\$ 27,987.88)$. The main effect of information was non-significant $\left(F(1,606)=0.84, p=.36, \eta^{2}=.001\right)$. Importantly, there was also a significant information $\mathrm{x}$ quotient interaction $\left(F(1,606)=52.07, p<.001, \eta^{2}=.045\right)$.

Tukey-corrected post-hoc tests showed that in the high quotient condition, having incomplete information resulted in lower estimates $(M=\$ 71,747.38, \mathrm{SD}=\$ 33,112.92)$ than having complete information $(M=\$ 86,517.28, \mathrm{SD}=\$ 29,691.20, t(606)=4.24, p<.001, d=$ 
0.47). However, in the low quotient condition, having incomplete information resulted in higher estimates $(M=\$ 36,424.21, \mathrm{SD}=\$ 33,518.24)$ than having complete information $(M=$ $\$ 17,350.31, \mathrm{SD}=\$ 16,537.99, t(606)=-5.79, p<.001, d=0.72)$. That is, incomplete information led to estimates assimilating towards their presumed prior.

We also coded estimates as calculation if the estimate was within $5 \%$ of the true quotient (Morwitz et al. 1998), or as strictly using the prior if the estimate was within 5\% of $\$ 50,000$ (because we expected the average perceived typical salary to be somewhere between the US median individual and household incomes [i.e., between about $\$ 33,000$ and $\$ 63,000$; US Census Bureau 2018], we chose this as a salient round anchor, though this provides a conservative test of our proposition as it assumes no heterogeneity in individuals' priors). Inspecting these estimates revealed that $33 \%$ of estimates were accurate in the low quotient condition and $45 \%$ were accurate calculations in the high quotient condition; $6 \%$ of estimates were within five percent of the prior in the low quotient condition while $4 \%$ of estimates were within five percent of the prior in the high quotient condition. Therefore, a majority of participants produced estimates that were not that close to the prior, nor to the accurate response. Thus, most individuals used a strategy other than calculation or strictly their prior, but some combination in between, in line with our predictions.

Deviations. A two-way ANOVA with information and quotient as factors found a significant effect of Quotient $\left(F(1,606)=259.19, p<.001, \eta^{2}=.28\right)$, such that deviations were more positive (i.e., more overestimation vs. underestimation) for the low quotient condition $(M=15,794.67, \mathrm{SD}=27,987.88)$ than for the high quotient condition $(M=-$ $21,646.86, \mathrm{SD}=32,205.07)$. The main effect of Information was non-significant $(F(1,606)=$ $\left..84, p=.359, \eta^{2}=.001\right)$. Importantly, there was also a significant Information $\mathrm{x}$ Quotient interaction $\left(F(1,606)=52.07, p<.001, \eta^{2}=.045\right)$. 
In the high quotient condition, participants underestimated median employee pay more in the incomplete information condition $(M=-29,252.62, \mathrm{SD}=33,112.92)$ compared to the complete information condition $(M=-14,483.72, \mathrm{SD}=29,691.20 ; t(606)=4.42, p<$ $.001, d=0.47)$. However, in the low quotient condition, participants overestimated median employee pay more in the incomplete information condition $(M=25,424.21, \mathrm{SD}=$ $33,518.24)$ compared to the complete information condition $(M=6,350.31, \mathrm{SD}=16,537.99$, $t(606)=-5.79, p<.001, d=0.72)$.

Moderated mediation. We ran a moderated mediation model using model 7 of the PROCESS SPSS macro (5,000 bootstraps; Hayes 2013), with information (complete vs. incomplete) as the independent variable, participants' estimation of salary as the mediator, employee pay fairness as the dependent variable, and quotient (high vs. low) as the moderator of the a-path. The moderated mediation effect was significant (index $(\mathrm{SE})=0.69(0.11), 95 \%$ CI $[0.49 ; 0.92])$. In the high quotient condition, having incomplete information (vs. having complete information) led to lower estimates, which in turn resulted in reduced fairness perceptions $(a b(\mathrm{SE})=-0.30(.08), 95 \% \mathrm{CI}[-0.16 ;-0.47])$. In the low quotient condition, having incomplete information (vs. having complete information) led to higher estimates, which in turn resulted in greater fairness perceptions $(a b(\mathrm{SE})=0.39(0.07), 95 \% \mathrm{CI}[0.26$; 0.53]). This analysis provides support for the notion that overestimation and underestimation of salary levels mediates the effect of presenting salaries (vs. not) on salary fairness judgments. 


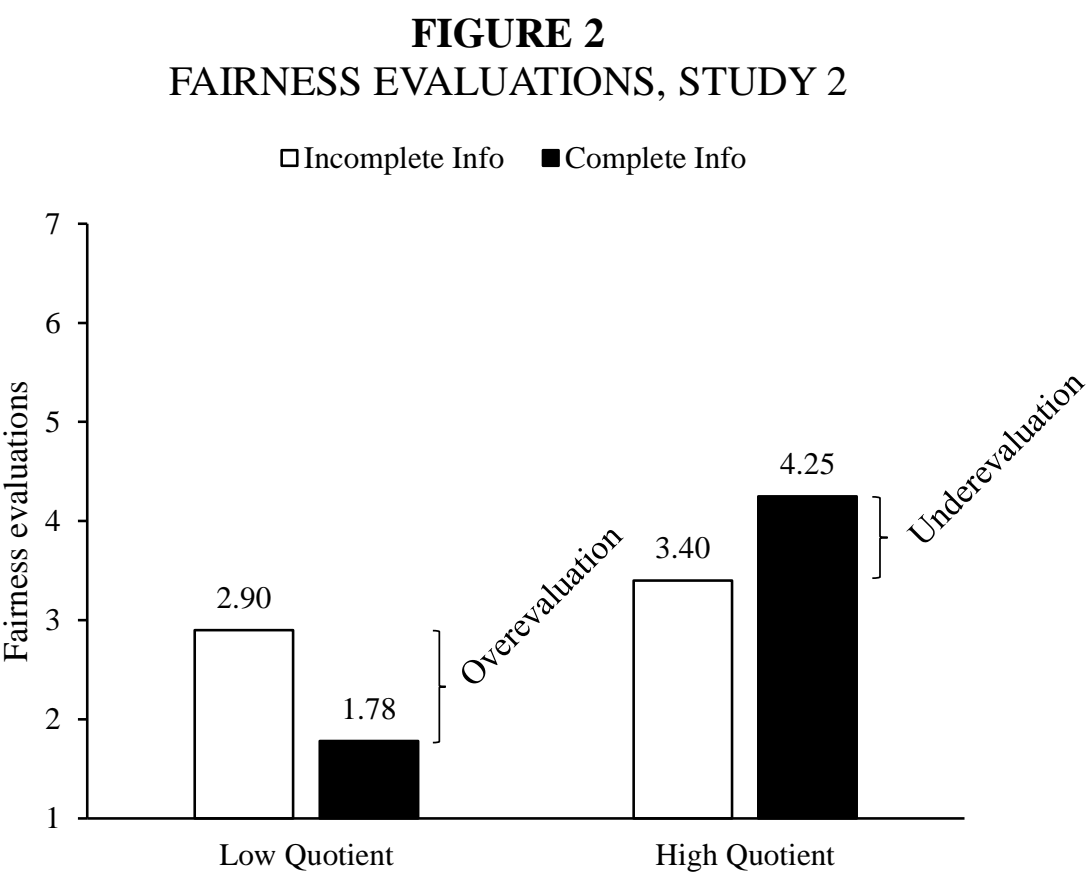

Discussion

This study replicates the results of the previous studies: when observers have to compute their own estimates of a target quotient, they tend to overestimate values below their prior and underestimate values above their prior.

One limitation of the studies we have reported thus far is that they do not directly assess the use of the prior value. Rather, we selected quotients that were lower or higher than what we expected to be the typical or average value that would be incorporated as a prior and find that estimates resolve consistent with our predictions. We address this in the next study by directly measuring what is seen as a typical salary and identifying its predictive value in how individuals arrive at quotient estimates to provide more direct process evidence. Because we plan to zoom in on the process at play when individuals do not have complete information, we focus on the incomplete information condition in the next study. 


\section{STUDY 3 - PROCESS EVIDENCE: USE OF SPONTANEOUS ANCHORS}

In this study, we investigate whether the typical level of an attribute indicated by consumers can predict the result of consumers' divisions. This study was preregistered at http://aspredicted.org/blind.php?x=rw8mk4.

Method

We recruited 584 participants on Mechanical Turk and excluded responses from those who indicated they had suffered a fatal heart attack, leaving 534 responses (328 males, 204 females, 2 prefer not to disclose, $M_{\text {age }}=38.1$ years). Participants were first asked what they thought the average American employee makes per year on a sliding scale from $\$ 0$ to $\$ 120,000$, which served as our measure of perceived typical salary. After completing about five minutes of filler tasks, participants were randomized to one of two quotient conditions: low or high. In both conditions, they were informed that at a technology company, the CEO:average salary ratio was 400:1. In the low (high) quotient condition, they were also told the CEO makes about $\$ 6$ million (\$42 million). Thus, in the low quotient condition, the true average employee salary was $\$ 15,000$, while in the high quotient condition, the average employee salary was $\$ 105,000$. Because we expected the perceived typical salary to be somewhere between the US median individual and household incomes (i.e., between about $\$ 33,000$ and $\$ 63,000$; US Census Bureau 2018), we expected the typical salary to be above the true average salary in the low quotient condition, and below the true average salary in the high quotient condition, to allow a good test of our hypotheses that consumers overestimate 
the quotient for values that are low and underestimate it for values that are high. Participants in the high (low) quotient condition were shown the following scenario:

Felet is a technology company based in Oakland, California.

The CEO makes \$42 million/year (\$6 million/year).

The CEO makes 400 times more money than the average employee at Felet.

After viewing the salary information, participants estimated the average employee salary at the company on a sliding scale from $\$ 0$ to $\$ 120,000$. We used these estimates to compute their deviations and absolute deviations from the true average employee salaries in their respective conditions.

Results

Typical Salary. First, we confirmed that perceived typical salary did not significantly vary across the conditions $(F(1,532)=.01, p>.90)$. The perceived typical salary was between individual and household incomes $(M=\$ 47,767.71, \mathrm{SD}=\$ 18,384.02)$, indicating that participants had a somewhat accurate idea of salary levels.

Estimates. A regression with condition (coded: low quotient $=-.50$ and high quotient $=.50)$ and mean-centered typical salary as predictors revealed main effects of condition $(b=$ $18,813.74, t(530)=8.72, p<.001)$ and perceived typical salary $(b=.57, t(530)=9.75, p<$ $.001)$. Their interaction was not statistically significant $(b=-.15, t(530)=-1.25, p>.21)$. As expected, estimates were higher when the actual quotient was higher $\left(M_{\text {low }}=\$ 40,346.32\right.$, 
$\mathrm{SD}_{\text {low }}=\$ 24,273.04$ vs. $M_{\text {high }}=\$ 59,051.06, \mathrm{SD}_{\text {high }}=\$ 28,986.29 ;$ see Figure 3), and, critically, the perceived typical salary also exerted a positive effect on estimates.

In order to explore which strategies participants used when estimating, we also coded estimates as calculation if the estimate was within $5 \%$ of the true quotient (Morwitz et al. 1998), or as strictly using the prior if the estimate was within 5\% of their perceived typical salary. Inspecting these estimates revealed that $18 \%$ of estimates were accurate in the low quotient condition and $17 \%$ were accurate calculations in the high quotient condition; $13 \%$ of estimates were within five percent of the prior in the low quotient condition while $11 \%$ of estimates were within five percent of the prior in the high quotient condition. Again, this means that most individuals used a strategy other than calculation or strictly their prior, but some combination in between, in line with our predictions.

Deviations. Per our hypotheses, deviations in the low condition (where the typical salary was above the true average) were on average significant overestimates of the true quotient $(M=25,346.32, \mathrm{SD}=24,273.04 ; t(530)=15.90, p<.001)$, but deviations in the high quotient condition (where the typical salary was below the true average) were on average significant underestimates of the true quotient $(M=-45,905.98, \mathrm{SD}=28,986.29$; $t(530)=31.48, p<.001)$. 
FIGURE 3 ESTIMATES, STUDY 3

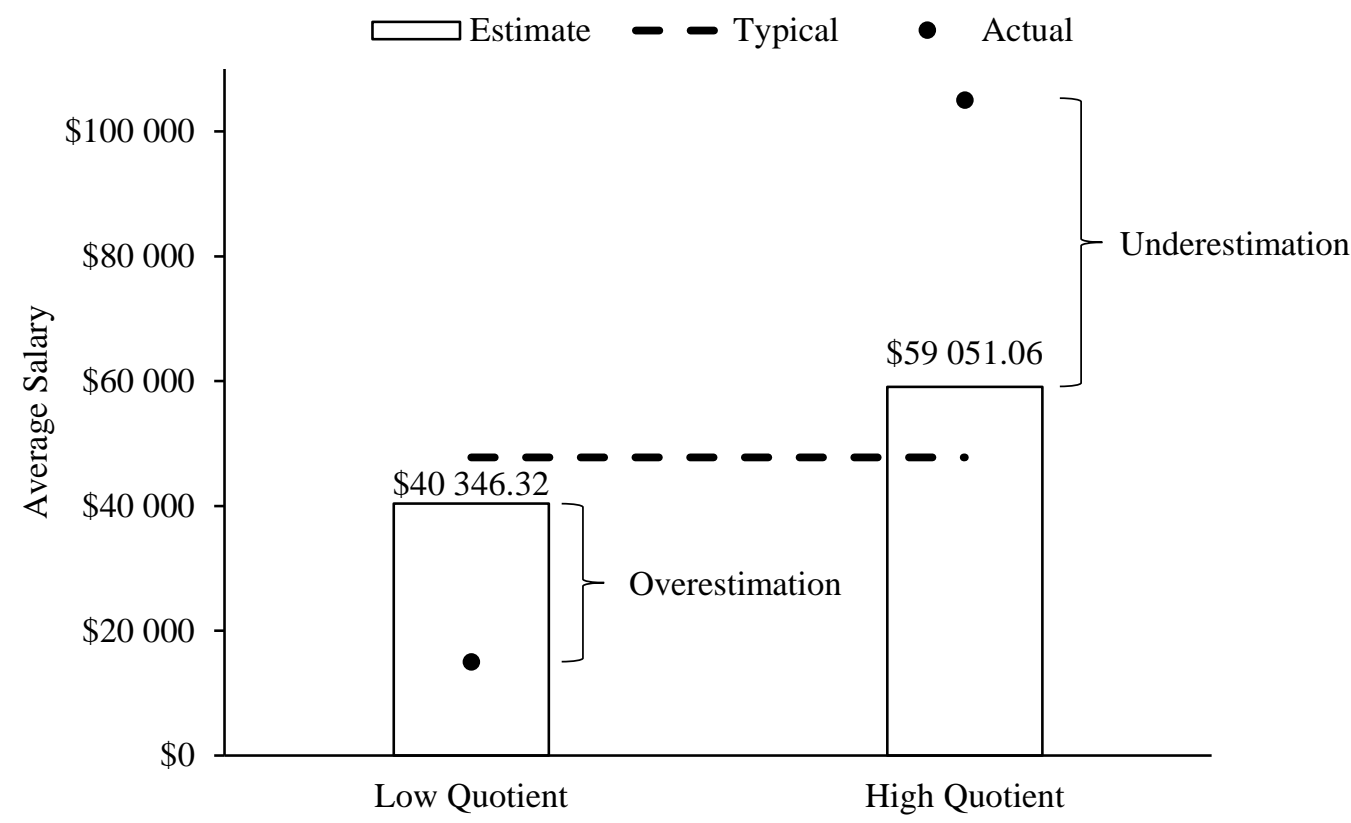

Discussion

The deviations and regression results provide converging evidence that individuals incorporate their perceived typical value into their quotient estimates. This is consistent with our hypothesis that typical attribute levels that people store in memory are influencing their divisions, leading consumers to overestimate the result of a division if the attribute is on the lower end of the attribute range, and underestimate it when the attribute is on the higher end of the attribute range. One limitation of this study is that by asking participants what the typical salary was, we could have primed them with a specific amount that they would not have used in their estimation otherwise. In the previous and next studies, however, we find 
similar effect sizes of both under- and overestimation without asking participants about their priors, which speaks against a "priming" account of the results of this study.

Next, we extend our investigation to company perceptions and human resources consequences.

\section{STUDY 4 - COMPANY PERCEPTIONS: CONSUMER AND HUMAN RESOURCES IMPLICATIONS}

This study tests whether over and underestimation of salary fairness has substantial effects on the company's image and on interest towards the company, through employee salary fairness. We also test whether such perceptions influence consumers' interest towards the company services. This study was preregistered at http://aspredicted.org/blind.php? $\mathrm{x}=\mathrm{mh} 6 \mathrm{~kb} 7$.

Method

We recruited 602 participants from Amazon Mechanical Turk (249 males, 353 females; $\left.M_{\text {age }}=39.24, S D_{\text {age }}=12.50\right)$. Participants were randomly assigned to a 2 (information: incomplete, complete) x 2 (quotient: low, high) design. Participants were shown the following scenario (in the complete information condition, they were also shown the information in square brackets; in round brackets, the amount shown in the high quotient condition): 
Nalis, an Internet e-book company based in Tampa (FL), has about 3,000 employees and a revenue of about $\$ 300$ million per year.

CEO pay at Nalis is around $\$ 1.3(10)$ million per year.

[Median employee pay at Nalis is $\$ 13(100)$ thousand a year.]

CEO pay is 100 times higher than median employee pay.

Participants were then asked to rate employee salary fairness on an item anchored at 1 (not at all) and 7 (very much). They also rated their perceptions of employee well-being at the company using six items (happy, growing, thriving, satisfied in their job, under pressure [reversed], stressed [reversed], $\alpha=.87$; Benedetti and Chen 2018) and rated their level of interest in working for the company (Benedetti and Chen 2018). All of these questions were asked on 1-7 scales anchored at $1=$ Not at all and $7=$ Very much. We also collected several other measures, which we report and analyze in detail in the Web Appendix.

Results

Fairness. A two-way ANOVA with information and quotient as factors found a significant effect of quotient $\left(F(1,598)=123.54, p<.001, \eta^{2}=.151\right)$, such that fairness was perceived as higher for the high quotient $(M=4.15, \mathrm{SD}=1.88)$ than for the low quotient $(M$ $=2.57, \mathrm{SD}=1.88)$. The main effect of Information was not statistically significant $(F(1,598)$ $\left.=.724, p=.395, \eta^{2}=.001\right)$. Importantly, there was also a significant information $\mathrm{x}$ quotient interaction $\left(F(1,598)=97.74, p<.001, \eta^{2}=.119\right)$.

In the high quotient condition, participants rated employee pay as less fair in the incomplete information condition $(M=3.39, \mathrm{SD}=1.74)$ compared to the complete 
information condition $(M=4.91, \mathrm{SD}=1.70) ; t(598)=-7.59, p<.001, d=0.89)$. In line with our prediction, consumers under-evaluated pay fairness. However, in the low quotient condition, participants rated employee pay as more fair in the incomplete information condition $(M=3.21, \mathrm{SD}=1.91)$ compared to the complete information condition $(M=1.93$, $\mathrm{SD}=1.61 ; t(598)=6.39, p<.001, d=0.73)$. In line with our prediction, consumers overevaluated pay fairness.

Perceived workers'well-being. A two-way ANOVA with information and quotient as factors found a significant effect of quotient $\left(F(1,598)=139.05, p<.001, \eta^{2}=.167\right)$, such that well-being was perceived as higher for the high quotient $(M=4.22, \mathrm{SD}=0.79)$ than for the low quotient $(M=3.39, \mathrm{SD}=1.05)$. The main effect of information was also statistically significant $\left(F(1,598)=6.49, p=.011, \eta^{2}=.008\right)$. Importantly, there was also a significant information $\mathrm{x}$ quotient interaction $\left(F(1,598)=87.63, p<.001, \eta^{2}=.105\right)$.

In the high quotient condition, participants rated employee well-being as lower in the incomplete information condition $(M=3.98, \mathrm{SD}=0.82)$ compared to the complete information condition $(M=4.46, \mathrm{SD}=0.69) ; t(598)=-4.82, p<.001, d=0.63)$. In line with our prediction, consumers under-evaluated employee well-being. However, in the low quotient condition, participants rated employee well-being as higher in the incomplete information condition $(M=3.81, \mathrm{SD}=0.99)$ compared to the complete information condition $(M=2.97, \mathrm{SD}=0.93 ; t(598)=8.42, p<.001, d=0.87)$. In line with our prediction, consumers over-evaluated employee well-being.

Employment interest. A two-way ANOVA with information and quotient as factors found a significant effect of quotient $\left(F(1,598)=141.74, p<.001, \eta^{2}=.172\right)$, such that 
employment interest was higher for the high quotient $(M=4.41, \mathrm{SD}=1.80)$ than for the low quotient $(M=2.73, \mathrm{SD}=1.88)$. The main effect of Information was not statistically significant $\left(F(1,598)=3.10, p=.079, \eta^{2}=.004\right)$. Importantly, there was also a significant Information x Quotient interaction $\left(F(1,598)=80.12, p<.001, \eta^{2}=.097\right)$.

In the high quotient condition, participants rated their interest in employment as lower in the incomplete information condition $(M=3.90, \mathrm{SD}=1.74)$ compared to the complete information condition $(M=4.91, \mathrm{SD}=1.72) ; t(598)=-5.09, p<.001, d=0.59)$. However, in the low quotient condition, participants rated their interest in employment as higher in the incomplete information condition $(M=3.84, \mathrm{SD}=1.97)$ compared to the complete information condition $(M=1.97, \mathrm{SD}=1.45 ; t(598)=7.57, p<.001, d=0.87)$.

Interest in company's services. A two-way ANOVA with information and quotient as between-subjects factors showed a significant effect of information shown, $F(1,598)=6.98$, $p=.008, \eta^{2}=.011$, a significant effect of quotient, $F(1,598)=30.24, p<.001, \eta^{2}=.046$, and a significant two-way interaction between information and quotient, $F(1,598)=23.49, p<$ $.001, \eta^{2}=.036$

Post-hoc comparisons (Tukey corrected) showed that when quotient level was low, there was a significant difference between the incomplete information condition $(M=3.75$, $S D=1.87)$ and the complete information condition $(M=2.62, S D=1.74), \mathrm{t}(598)=5.30, p<$ $.001, d=0.62$. When the salary level was high, there was no significant difference, between the incomplete information condition $(M=3.85, S D=1.85)$, and the complete information condition $(M=4.18, S D=1.93), t(598)=-1.56, p=.40, d=0.18$. 
Moderated mediation. We ran two moderated mediation analyses with model 7 of the PROCESS macro for SPSS (5,000 bootstraps; Hayes 2013). The first included information (complete vs. incomplete) as the independent variable, pay fairness as the mediator, perceived well-being as the dependent variable, and quotient (high vs. low) as a moderator of the a-path, and found that the index of moderated mediation was significant (index $(\mathrm{SE})=$ 1.36 (.0.15), $95 \% \mathrm{CI}[1.06 ; 1.66])$. In the high quotient condition, having complete information (vs. lacking information) led to lower fairness perceptions, which in turn resulted in heightened well-being perceptions $(a b(\mathrm{SE})=0.74(0.10), 95 \% \mathrm{CI}[0.54 ; 0.94])$. In the low quotient condition, having complete information (vs. lacking information) led to higher fairness perceptions, which in turn resulted in lowered well-being perceptions $(a b(\mathrm{SE})=-$ $0.62(0.10), 95 \%$ CI $[-0.83 ;-0.42])$.

The second moderated mediation analysis, with information as the independent variable, pay fairness as the mediator, employment interest as the dependent variable, and quotient (high vs. low) as a moderator of the a-path, also found that the index of moderated mediation was significant (index $(\mathrm{SE})=1.96(0.22), 95 \%$ CI $[1.53 ; 2.39])$. In the high quotient condition, having complete information (vs. lacking information) led to lower fairness perceptions, which in turn resulted in heightened employment interest, $(a b(\mathrm{SE})=$ $1.06(0.15), 95 \% \mathrm{CI}[0.79 ; 1.36])$. In the low quotient condition, having complete information (vs. lacking information) led to higher fairness perceptions, which in turn resulted in greater employment interest, $(a b(\mathrm{SE})=-0.89(0.15), 95 \%$ CI $[-1.19 ;-0.60])$.

Discussion 
This study indicates that the effect of incomplete information on fairness perceptions also leads to a host of important practical results- biased perceptions of employee well-being as well as changes in interest in employment at the firm. On the consumer side, we show that such misperceptions significantly influence people's interest towards the company's services. Next, we extend our investigation to further consumer behavior implications.

\section{STUDY 5 - CONSUMER BEHAVIOR IMPLICATIONS: EFFECTS ON PRODUCT CHOICE AND WTP}

In this study we tested the consequences of salary underestimation on actual product choice and willingness-to-pay. This study was preregistered at http://aspredicted.org/blind.php?x=yr68bp.

Method

We recruited 800 US participants from Amazon Mechanical Turk (403 males, 397 females, $M_{\text {age }}=38.8$ ). Participants were randomly assigned to one of two information conditions: incomplete or complete. In the incomplete information condition, they were shown the following scenario (in the complete information condition, they were also shown the information in brackets):

YUM! Brands, a food company based in Louisville (KY), has about 15,000 employees and a revenue of above $\$ 1$ billion per year.

David Novak, CEO of YUM! is paid around \$2.7 million per year. 
[Median employee pay at YUM! is \$9 thousand a year.]

CEO pay is 300 times higher than median employee pay.

Given our results in Study 3 regarding typical pay, we expected this salary to be "low" and thus subject to an overestimation effect. Participants were then asked to rate employee salary fairness on an item anchored at 1 (not at all) and 7 (very much). Then, they were asked to estimate the median yearly employee salary on a slider from $\$ 0$ to $\$ 50,000$. Then, they were asked to state their willingness-to-pay (WTP) for a \$10 gift card to buy YUM! Products on a slider going from $\$ 0$ to $\$ 20$. Then, they were told (truthfully) that they had received an e-book as a gift, and they could choose one among two, one being a business book authored by YUM! CEO David Novak, and the other one being a recipe book authored by Daniel Cook. They could see the title and the cover of both books. When they chose their book, they were sent to a link to download the book, in PDF format.

Results

Fairness. Participants in the incomplete information condition evaluated the employees' salaries as fairer, $(M=3.30, \mathrm{SD}=1.74)$ compared to participants in the complete information condition $(M=2.45, \mathrm{SD}=1.72, t(798)=6.94, p<.001, d=0.49)$.

Estimates. Participants in the incomplete information condition estimated the employees' salaries to be higher $(M=\$ 29,156.86, \mathrm{SD}=\$ 12,969.97)$ compared to participants in the complete information condition $(M=\$ 17,288.87, \mathrm{SD}=\$ 11,824.74, t(798)$ $=13.52, p<.001, d=0.96)$. Note that taking the median estimate results in more accurate 
estimations for the complete information condition $(\mathrm{Mdn}=\$ 9,501)$ but not for the incomplete information condition $(\mathrm{Mdn}=\$ 30,166)$.

We also coded estimates as calculation if the estimate was within $5 \%$ of the true quotient (Morwitz et al. 1998), or as strictly using the prior if the estimate was within 5\% of $\$ 50,000$ (because we expected the average perceived typical salary to be somewhere between the US median individual and household incomes [i.e., between about $\$ 33,000$ and $\$ 63,000$; US Census Bureau 2018], we chose this as a salient round anchor, though this provides a conservative test of our proposition as it assumes no heterogeneity in individuals' priors). Inspecting these estimates revealed that $46 \%$ of estimates were accurate in the complete information condition and $6 \%$ were accurate calculations in the incomplete information condition; $3 \%$ of estimates were within five percent of the prior in the complete information condition while $8 \%$ of estimates were within five percent of the prior in the incomplete information condition. These results are similar to those of Studies 2 and 3, showing a mixture of strategies in consumers' division processes.

WTP. Participants in the incomplete information condition reported higher WTP for a $\$ 10$ gift card of YUM! Products $(M=\$ 6.14, \mathrm{Mdn}=\$ 6.20, \mathrm{SD}=\$ 3.79)$ compared to participants in the complete information condition $(M=\$ 5.36, \mathrm{Mdn}=\$ 5.07, \mathrm{SD}=\$ 3.87$, $t(798)=2.89, p=.004$, Mann-Whitney $\mathrm{U}=70,449, p=.003, d=0.21)$. This effect is practically significant, as it corresponds to an average increase in WTP of $\$ 0.78$, or $15 \%$, and to a median increase in WTP of $\$ 1.13$, or $22 \%$.

E-book choice. A logistic regression found a significant effect of information condition on e-book choice $(b(\mathrm{SE})=0.53(0.15), z=3.67, p<.001)$. In the complete 
information condition, 140/398 (35\%) chose to download the book by the YUM! CEO. In the incomplete information condition, 193/402 participants (48\%) chose to download the book by the YUM! CEO. This increase is both statistically significant and practically substantial- the CEO book was $37 \%$ more likely to be chosen in the incomplete information condition.

Serial mediation. We ran two serial mediation analyses using model 6 of the PROCESS macro for SPSS (Hayes 2013; 5,000 resamples). The first mediation analysis included information condition as the independent variable, salary estimates as the first mediator, fairness as the second mediator, and WTP as the dependent variable. The indirect effect was statistically significant $(a b(\mathrm{SE})=0.22(0.05), 95 \%$ CI $0.13 ; 0.33])$, indicating our hypothesized process affected WTP. The second mediation analysis was a similar mediation analysis using model 6 of the PROCESS macro for SPSS (Hayes 2013; 5,000 resamples), with information condition as the independent variable, salary estimates as the first mediator, fairness as the second mediator, and with e-book choice as the dependent variable. The indirect effect was again significant $(a b(\mathrm{SE})=0.13(0.03), 95 \%$ CI 0[.08; 0.19]), indicating our hypothesized process affected product choice as well.

Discussion

This study replicates previous studies and provides evidence that the overestimation that occurs when consumers estimate a quotient below their prior has an impact on consumerand managerially-relevant dependent variables, WTP and product choice. 
Our studies show that consumers under-evaluate an attribute when the target quotient is above their prior but over-evaluate an attribute when the target quotient is below their prior. These evaluations are driven by under- and over-estimates resulting from the use of the prior information available in memory. We also show that relying on priors for these division problems not only biases attribute perceptions but also has consequences for hiring-relevant impressions about the firm, willingness-to-pay, and product choice.

Theoretical contributions

We make several theoretical contributions. First, we contribute to the research about consumers' intuitive approaches to division problems. While previous research has studied when consumers actually calculate (Biswas et al. 2013) and how consumers calculate (Villanova and Bagchi 2020), insights into intuitive approaches to division problems are lacking. Often, incorrect calculation is simply labeled the result of opaque heuristic processing strategies, but the underlying process is not explained in detail. The present research identifies relying on a prior as an alternative for division problems. This is an important advancement for numerical cognition, of great potential given the ubiquity of numerical stimuli in the marketplace (Landy, Guay, and Marghetis, 2017; Landy, Silbert, and Goldin, 2013) and potential applications in a wide range of fields, from product attribute evaluation to the impact of income inequality on consumers.

Second, we contribute to the research on anchoring. Previous research has neglected to investigate how consumers use prior information as an anchor for product and attribute judgments, focusing instead on anchors provided ad hoc, such as by spinning a wheel 
(Tversky and Kahneman 1974a), the simple presentation of a randomly generated number (Smith and Windschitl 2011), or the induction of plausible numbers through leading questions (Epley and Gilovich 2006). This gap is surprising in light of the many ways in which consumers are known to use prior experience (Alba and Hutchinson 1987; Hong and Sternthal 2010). In our research, we show that consumers rely on natural anchors that they generate spontaneously, without experimenter intervention, using their knowledge of the attribute in question. Ülkümen, Thomas, and Morwitz (2008) have proposed spontaneous reliance on self-generated anchors, but in the context of determining values in financial decision-making (in contrast to estimated solutions on which to base evaluations, studied here). Our research sheds light on the role of consumers' prior attribute information, highlighting its relevance to attribute estimation and evaluation.

In our studies, some participants accurately calculated the quotient, and few participants relied solely on their prior for estimates. These two strategies are qualitatively different from prior anchoring strategies that have been proposed, notably, anchoring-andadjustment, in which a single participant that exhibits anchoring is supposed to first rely on the anchor, then adjust their estimate towards the true value. Yet, if these were the only two strategies employed, the final effects would have been indistinguishable from those predicted by anchoring-and-adjustment. By interrogating the actual strategies used, we found the majority seemed to rely on a third strategy that partially incorporated their prior, which is qualitatively more similar to anchoring-and-adjustment. Our findings therefore nuance the literature about the very process of anchoring, by identifying multiple strategies, which, in turn, present final results that are indistinguishable from anchoring.

Third, we contribute to the research about perceptions of economic inequality. Inequality perceptions are important for demands of social change (Niehues 2014), but 
people are remarkably inaccurate at estimating inequality both at the societal and at the company level (Gimpelson and Treisman 2018). Given that division and numerical data of this type is implicated in the judgments of within-company income inequality (Benedetti and Chen 2018; Eriksson and Simpson 2012; Ziano et al. 2019), the present work contributes to this line of research, clarifying how incomplete income inequality information is perceived and evaluated and its consequences for consumer behavior and perceptions of the company.

Practical implications

This paper offers implications for the marketing and the policymaking around any product or company attribute that can be a result of a division. Marketing managers may be tempted to omit the attribute itself if the product they are selling has an important attribute that is worse than typical, knowing that consumers may overestimate it and consequently evaluate the attribute and the product more favorably than they would if it were provided to them. Therefore, policymakers may wish to regulate how this information is provided in promotional materials or descriptions of the product in the popular and specialized press, perhaps making sure that companies are not taking advantage of consumers' numerical cognition biases. For instance, when advertising a gas-guzzling SUV with an especially low fuel efficiency as measured in miles-per-gallon, one implication is that it is a good thing that policy-makers require companies communicate the actual miles-per-gallon value rather than leaving it to the average consumer to compute an overestimated value. On the other hand, companies that are marketing a product with an especially high attribute value may wish to make sure they present the actual value to avoid underestimation. 
Since we showed that consumers have internal anchors that affect their attribute estimates, we wish to highlight that companies can identify and investigate the natural anchors used by consumers before they decide on communication and advertising strategies. For instance, when companies wish to highlight a specific attribute through an advertising campaign, they must be cognizant that consumers may utilize natural anchors that bias evaluations in a way contrary to the marketing managers' intentions. Companies highlighting attributes on the lower- or higher-end of the range in the marketplace may therefore pay special attention to clear communications, as consumers may merge the attribute with their natural prior and therefore end up with a biased attribute evaluation that nullifies the intended effects of an advertising campaign.

This paper particularly offers some indications about the communication of company compensation data. We find that consumers penalize companies with higher employees' salaries and reward companies with lower employees' salaries when they have to calculate salaries themselves. It follows that managers at firms where employees' salaries are higher should emphasize the actual median employee salaries, for instance in advertising or corporate communications. On the other hand, companies who pay lower salaries have every incentive not to make it public. Since consumers form a biased view of employee salaries when only CEO pay and pay ratio are provided, policymakers may want to implement more forceful regulations on how within-company income inequality is presented. For now, such information is only available on official statements, and spread out by the news media. However, since consumers employ a biased method to estimate employee salary, regulators and policymakers may want to mandate more widespread communication of company compensation in spots accessible and available to consumers with little effort (e.g., on the company's commercial website or at the place of business, rather than financial statements), 
especially for industries that pay lower salaries and have an incentive to make such information hard to find.

Future research

The present paper also offers avenues for additional research. The first one pertains to anchoring and strategies relative to it. We have identified two main ways in which people anchor. By looking at the distribution of past experimental data about anchoring that includes consumer-generated priors, one could test whether the dual process that produces results indistinguishable from anchoring can explain findings beyond division operations.

Other research directions regard the investigation of other arithmetical operations. While prior research has identified anchoring and adjustment as an alternative strategy for addition or subtraction problems, and this research identifies reliance on a prior as an alternative strategy for division problems, exploring alternative strategies for multiplication seems to be a natural extension. Extant research has studied biased approaches in assessing multiplicands (e.g., a discount to later be multiplied; Chen and Rao 2007; Davis and Bagchi 2018) and in simplifying multiplication problems by rounding prior to using the algorithm (Dowker et al. 1996), but what is the nature of the dominant alternative strategy, if there is one? In Tversky and Kahneman (1974, p. 1128) anchoring and adjustment is assumed to be used for a long multiplication problem where individuals can generate an initial product from "the first few steps of multiplication," but what of shorter multiplication problems consumers may be more likely to encounter that do not lend themselves to generating a tentative product? 
Next, because confidence in an initial estimate should reduce adjustment (Ülkümen et al. 2008), it is possible that those who are more confident about their priors may exhibit greater over-/under-estimation tendencies relative to those who are less confident. This, however, would critically depend on individuals' propensities to marshal the division algorithm, leaving open questions about how prior confidence and predictors of calculation may interact to affect final estimates.

We showed that people rely on their priors when they are making divisions, in a process that yields results very similar to anchoring, and that such a process is separate from an explanation that simply some people do the correct division, or at least come close to it, and other people strictly rely on their prior about the attribute. To what extent do people rely on each of these approaches when they complete classic anchoring tasks? Testing such a hypothesis would help advance ongoing research about the causes of anchoring (Bahník 2021; Epley and Gilovich 2006; Frederick and Mochon 2012; Lewis, Gaertig, and Simmons 2019) by focusing on different strategies that individuals pursue when anchoring rather than proposing a one-size-fits-all recipe.

Previous research has shown that people are quite inaccurate at estimating income and wealth inequality within their own countries (Gimpelson and Treisman 2018), with some research showing that Americans either underestimate (Norton and Ariely 2011) or overestimate (Chambers, Swan, and Heesacker 2014) the extent of economic inequality. Our research, however, shows that people are not that bad at estimating typical incomes, in line with previous research investigating drivers of perceived income inequality (Ziano et al. 2019). The reasons for this are still unclear but may perhaps be connected with the more extensive experience that most people have with salaries, as opposed to indicators of economic inequality. Future research may investigate which indicators are most adept for 
communicating the economic pictures, and for which objectives one or the other should be preferred. 


\section{REFERENCES}

Adams, J. Stacy and Sara Freedman (1976), "Equity Theory Revisited: Comments and Annotated Bibliography," Advances in Experimental Social Psychology, 9(C), 43-90.

Alba, Joseph W. and J. Wesley Hutchinson (1987), "Dimensions of Consumer Expertise," Journal of Consumer Research, 13(4), 411.

Ashcraft, Mark H. (1992), "Cognitive Arithmetic: A Review of Data and Theory,” Cognition, 44(1-2), 75-106.

Bagchi, Rajesh and Derick F. Davis (2012), “\$29 for 70 Items or 70 Items for \$29? How Presentation Order Affects Package Perceptions,” Journal of Consumer Research, 39(1), $62-73$.

Bahník, Štěpán (2021), “Anchoring without Scale Distortion,” Judgment \& Decision Making, $16(1), 131-41$

Bartels, Daniel M. (2006), "Proportion Dominance: The Generality and Variability of Favoring Relative Savings over Absolute Savings," Organizational Behavior and Human Decision Processes, 100(1), 76-95.

Benedetti, Arianna H. and Serena Chen (2018), "High CEO-to-Worker Pay Ratios Negatively Impact Consumer and Employee Perceptions of Companies,” Journal of Experimental Social Psychology, 79(February), 378-93.

Campbell, Alexia Fernández (2019), “CEOs Made 287 Times More Money Last Year than Their Workers Did," Vox.com.

Capon, Noel and Deanna Kuhn (1982), "Can Consumers Calculate Best Buys?,” Journal of Consumer Research, 8(4), 449-53.

Chambers, John, Lawton Swan, and Martin Heesacker (2014), “Better Off Than We Know: Distorted Perceptions of Income Inequality in America," Psychological Science, 25(2), 
613-18.

Cotte, June and Remi Trudel (2009), "Socially Conscious Consumerism: A Systematic

Review of the Body of Knowledge," Network for Business Sustainability.

Deloitte (2018), "Pay Ratios and Executive Pay Reporting BEIS Issues Legislation to Deliver Corporate Governance Reforms Including Pay Ratios."

Dowker, A N N, Amanda Flood, Christ Church, and Helen Griffiths (1996), "Estimation Strategies of Four Groups," Mathematical Cognition, 2, 113-35.

Epley, Nicholas and Thomas Gilovich (2006), "The Anchoring-and-Adjustment Heuristic

Why the Adjustments Are Insufficient," Psychological Science, 17(4), 311-18.

Eriksson, Kimmo and Brent Simpson (2012), "What Do Americans Know about Inequality?

It Depends on How You Ask Them," Judgment and Decision Making, 7(6), 741-45.

Fennell, John and Roland Baddeley (2012), “Uncertainty plus Prior Equals Rational Bias: An

Intuitive Bayesian Probability Weighting Function,” Psychological Review, 119(4), $878-87$.

Fox, Craig R. and Yuval Rottenstreich (2003), "Partition Priming in Judgment under Uncertainty," Psychological Science, 1(1), 195-200.

Frederick, Shane W. and Daniel Mochon (2012), “A Scale Distortion Theory of Anchoring," Journal of Experimental Psychology: General, 141(1), 124-33.

Furnham, Adrian and Hua Chu Boo (2011), "A Literature Review of the Anchoring Effect," Journal of Socio-Economics, 40(1), 35-42.

Gimpelson, Vladimir and Daniel Treisman (2018), "Misperceiving Inequality,” Economics and Politics, 30(1), 27-54.

Greenberg, Jon (2019), “Omar Garbles Details of McDonald's CEO and Typical Worker Pay," Politifact. 
Hitch, Graham J. (1978), “The Role of Short-Term Working Memory in Mental Arithmetic," Cognitive Psychology, 10(3), 302-23.

Hong, Jiewen and Brian Sternthal (2010), “The Effects of Consumer Prior Knowledge and Processing Strategies on Judgments," Journal of Marketing Research, 47(2), 301-11. Hooper, John (2013), “Switzerland Votes against Cap on Executive Pay,” The Guardian. Kervyn, Nicolas, ST Fiske, and Chris Malone (2012), "Brands as Intentional Agents Framework: How Perceived Intentions and Ability Can Map Brand Perception,” Journal of Consumer Psychology, 22(2).

Kiatpongsan, S. and M. I. Norton (2014), "How Much (More) Should CEOs Make? A Universal Desire for More Equal Pay,” Perspectives on Psychological Science, 9(6), 587-93.

Landy, David, B Guay, and T Marghetis (2017), "Bias and Ignorance in Demographic Perception.," Psychonomic bulletin \& review.

Landy, David, Noah Silbert, and Aleah Goldin (2013), "Estimating Large Numbers," Cognitive Science, 37(5), 775-99.

de Langhe, Bart and Stefano Puntoni (2015), "Bang for the Buck: Gain-Loss Ratio as a Driver of Judgment and Choice," Management Science, 61(5), 1137-63.

Lewis, Joshua, Celia Gaertig, and Joseph P. Simmons (2019), “Extremeness Aversion Is a Cause of Anchoring," Psychological Science, 30(2), 159-73.

Mishel, Lawrence and Jessica Schiedler (2017), “CEO Pay Remains High Relative to the Pay of Typical Workers and High-Wage Earners," Economic Policy Institue.

Mohan, Bhavya, Tobias Schlager, Rohit Deshpandé, and Michael I. Norton (2018), “Consumers Avoid Buying From Firms With Higher CEO-to-Worker Pay Ratios," Journal of Consumer Psychology, 28(2), 344-52. 
Morwitz, Vicki G, Eric A Greenleaf, Eric J Johnson, Vicki G Morwitz, Eric A Greenleaf, and Eric J Johnson (1998), “Consumers’ Reactions to Partitioned Prices Author(S):,” 35(4), 453-63.

Niehues, Judith (2014), Subjective Perceptions of Inequality and Redistributive Preferences: An International Comparison, IZA Bonn working papers.

Norton, M. I. and D. Ariely (2011), "Building a Better America--One Wealth Quintile at a Time," Perspectives on Psychological Science, 6(1), 9-12.

Parker, Melanie and Gaea Leinhardt (1995), "Percent: A Privileged Proportion," Review of Educational Research, 65(4), 421-81.

Rushe, Dominic (2019), “Top US Bosses Earn 278 Times More than Their Employees,” The Guardian.

Scheyder, Ernest (2017), “Exxon Mobil Boosted CEO Pay to \$17.5 Million for 2017," Reuters.com.

Security and Exchange Commission (2017), “Commission Guidance on Pay Ratio Disclosure."

Smith, Andrew R. and Paul D. Windschitl (2011), “Biased Calculations: Numeric Anchors Influence Answers to Math Equations," Judgment and Decision Making, 6(2), 139-46.

Trudel, Remi and June Cotte (2009), "Reward Or Punish: Willingness to Pay For EthicallyProduced Goods," in Advances in Consumer Research, ed. Angela Y. Lee and Dilip Soman, Duluth, MN, 229-32.

Tversky, Amos and Daniel Kahneman (1974a), "Judgement under Uncertainty: Heuristics and Biases," Science, 185(4157), 1124-31.

— (1974b), “Judgment under Uncertainty: Heuristics and Biases,” science, 185(4157), $1124-31$. 
Ülkümen, Gülden, Manoj Thomas, and Vicki G. Morwitz (2008), "Will i Spend More in 12 Months or a Year? The Effect of Ease of Estimation and Confidence on Budget Estimates," Journal of Consumer Research, 35(2), 245-56.

United States Environmental Protection Agency (2020), “The EPA Automotive Trends Report."

Zeithaml, Valarie A. (1988), "Consumer Perceptions of Price, Quality, and Value: A MeansEnd Model and Synthesis of Evidence," Journal of Marketing, 52(3), 2.

Ziano, Ignazio, Christophe Lembregts, and Mario Pandelaere (2019), Perceived Income Inequality: Why Pay Ratios Are Less Effective Than Median Incomes. 


\section{USING SELF-GENERATED PRIORS IN DIVISION LEADS TO BIASED CONSUMER JUDGMENTS}

\section{Web Appendix}

This Web Appendix contains the results of the analyses several additional measures that we collected in each study. We present them here for reason of space and transparency.

\section{Table of contents}

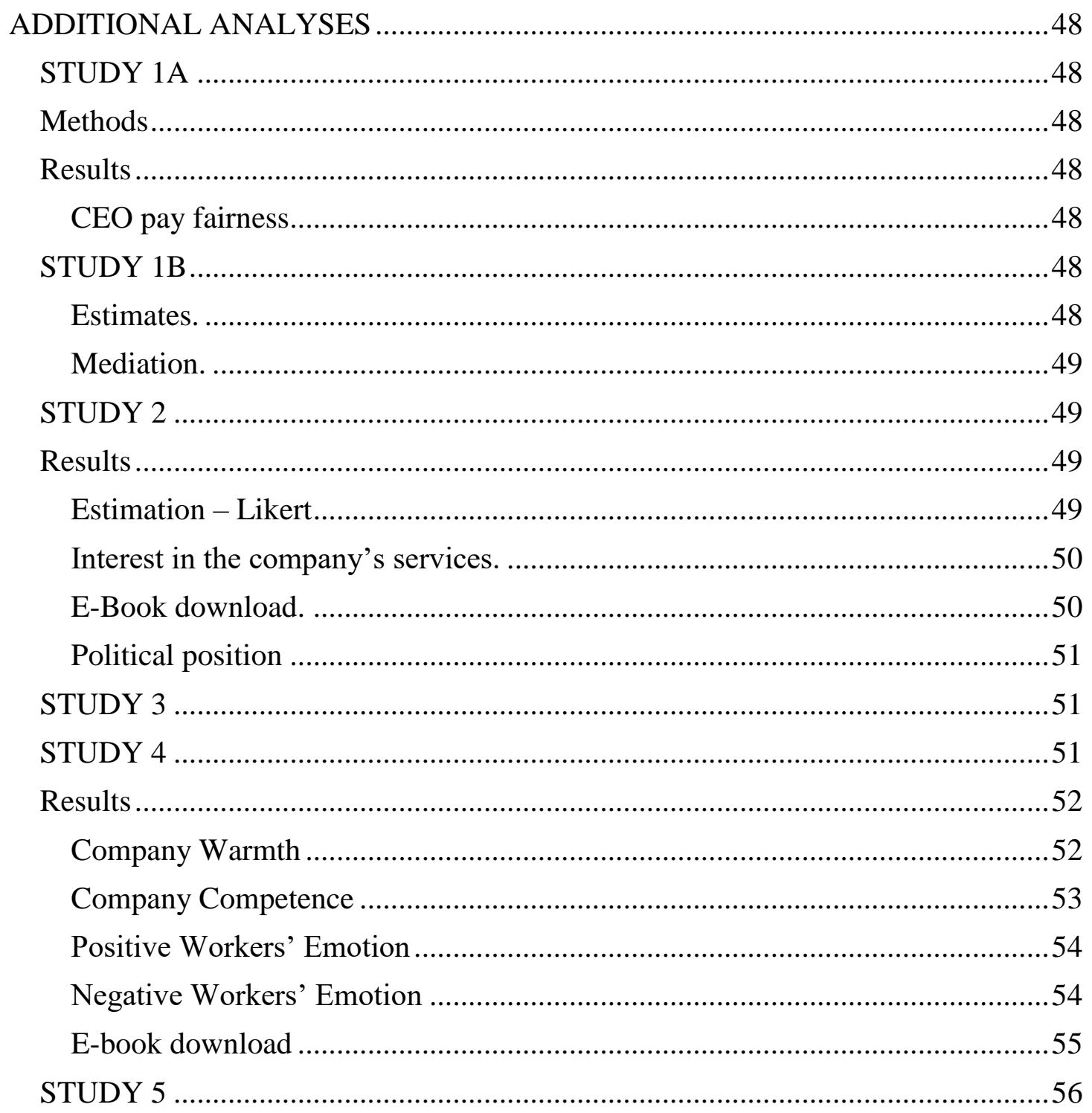




\section{ADDITIONAL ANALYSES}

\section{STUDY 1A}

Methods

All participants were asked four questions on 7-point Likert-type scales anchored at 1 = Not at all, 7 = Very much: "Is the CEO pay fair?"; "Is the CEO pay just?"; "Are employees pays fair?"; “Are employees' pays just?”. The two questions about the CEO pay fairness and the two questions about employee pay fairness both showed high Cronbach's alpha (CEO = .91 ; employee $=.97)$ and were thus averaged into two indices of CEO pay fairness and employee pay fairness.

Results

CEO pay fairness.

We did not find a significant difference between the complete information was shown $(M=3.30, \mathrm{SD}=1.71)$, and the incomplete information condition regarding CEO salary fairness, $(M=2.96, \mathrm{SD}=1.57), t(297)=-1.77, p=.078, d=0.20$.

\section{STUDY 1B}

\section{Estimates.}

Participants rated Car X as getting slightly better mpg $(M=13.69, \mathrm{SD}=7.02)$ in the incomplete condition compared to the complete condition $(M=12.85, \mathrm{SD}=4.36)$, albeit falling short of conventional significance threshold, Welch's $t(329.83)=-1.44, p=.15, d=$ 0.14. These results are not fully in line with our hypothesized process, as they fall short of conventional statistical significance, but do provide some indication that consumers' process is qualitatively in line with our hypotheses. 


\section{Mediation.}

We conducted a mediation analysis using information as the independent variable, mpg estimates as the mediator and fuel-efficiency evaluation as the dependent variable. The indirect effect (PROCESS model 4, Hayes 2013, 5000 bootstraps) fell just short of conventional statistical significance, $a b(\mathrm{SE})=.07(.059), 95 \%$ CI $[-.018, .20]$. However, this is unsurprising given that the results of estimates fell short of statistical significance.

There are several possibilities on how to interpret the results of Study 1b, which show an effect in line with our theorizing for attribute judgment, but not for attribute estimation. The first is a lack of statistical power. Perhaps we need a higher sample size to also detect an effect in attribute estimation, if the effect is close to the not statistically significant one that we observed in this study (in order to detect a Cohen's $d=0.15$ with $80 \%$ power and a twotailed alpha of 5\%, we would need around 800 total participants). A second possibility is that of a false negative - that is, as further studies repeatedly show, people do misestimate attribute level when having incomplete information in division, but in this study, because of statistical noise, we did not obtain a statistically significant effect. Nonetheless, we believe that it is important to report such analyses in the spirit of transparency.

\section{STUDY 2}

Results

\section{Estimation - Likert}

A two-way ANOVA with quotient and information as factors found no significant effect of information, $F(1,606)=0.73, p=.39, \eta^{2}=.001$, a significant effect of quotient, $F(1,606)=620.25, p<.001, \eta^{2}=.474$, and a significant interaction between level and information, $F(1,606)=81.03, p<.001, \eta^{2}=.062$. These results are in line with those of the slider estimation presented in the main paper. 
Interest in the company's services.

A two-way ANOVA with quotient and information as between-subjects factors showed a significant effect of information, $F(1,606)=7.42, p=.007, \eta^{2}=.012$, a significant effect of quotient level, $\mathrm{F}(1,606)=5.95, \mathrm{p}=.015, \eta^{2}=.009$, and a significant effect of the interaction between quotient level and information, $\mathrm{F}(1,606)=14.95, \mathrm{p}<.001, \eta^{2}=.024$. When the quotient was low, participants reported a higher level of interest in the company's services in the complete information condition than in the incomplete information condition, $d=0.53, p<.001$. When the quotient was high, participants level of interest in the company's services were similar in the complete and incomplete information condition, $d=$ $0.09, p=.85$. These results show that interest in the company services moved in sync with our manipulation, rewarding low-paying companies and penalizing well-paying companies when salaries are not shown.

\section{E-Book download.}

A logistic regression with e-book download as the dependent variable and quotient and information as independent variables found no effect of information, B $(\mathrm{SE})=.28(.25)$, $p=.27$, no effect of quotient, $\mathrm{B}(\mathrm{SE})=-.13(.24), p=.59$, and no effect of their interaction, $\mathrm{B}$ $(\mathrm{SE})=-.30(.35), p=.39$. It is likely that these results represent a mistake on the experimenter part, as the question was ill posed, such that there was no evident benefit or cost for participants to either choose or forgo to download the eBook. These results, however, should be taken with a grain of salt, as the eBook offered were the same across conditions and therefore participants may not have sufficiently connected them with the company and its salary. In further studies, we adopt a slightly different version of the same dependent variable with successful results, anchoring the product to the CEO. The notion that this measure was ill-posed, and therefore the results are attributable to the question formulation rather than to 
no effect of our manipulation on product choice is further supported by the results of the measure of interest in the company services reported and analyzed above.

\section{Political position}

A three-way ANOVA with information, quotient, and political ideology (indicated as "Democratic", "Independent", "Republican") as between-subjects factors could not find the predicted three-way interaction on employee fairness judgments, $F(2,598)=0.56, p=.57$, $\eta^{2}=.001$. Therefore, we found no evidence that political ideology affected the results we presented here. Our results seem driven by a cognitive process rather than a political partisanship effect.

\section{STUDY 3}

Absolute Deviations. A regression with condition (coded: low quotient $=-.50$ and high quotient $=.50)$ and mean-centered typical salary as predictors revealed a main effect of condition $(b=21,040.89, t(530)=10.01, p<.001)$ and an interaction of condition $\mathrm{x}$ perceived typical salary $(b=-1.08, t(530)=-9.45, p<.001)$. The main effect of typical salary was not statistically significant $(b=.09, t(530)=1.62, p>.10)$. As expected, in the low quotient condition, as perceived typical salary increased (that is, moved further away from the true quotient), misestimation increased as individuals' overestimates worsened ( $b=.63$, $t(530)=7.72, p<.001)$. In the high quotient condition, as perceived typical salary increased (that is, moved closer to the true quotient), misestimation decreased as individuals' underestimates abated $(b=-.45, t(530)=-5.62, p<.001)$.

\section{STUDY 4}

Participants were then asked to rate a) CEO pay fairness and employee salary fairness; b) Warmth (Warm, Caring, Friendly, Well-intentioned, $\alpha=.96$, averaged in a Warmth index) and Competence (Competent, Efficient, Capable, Skillful, $\alpha=.94$, averaged in a Competence 
index) of the company, both taken from (Fiske et al. 1999); c) The positive emotional status of employees at this company (Happy, Growing, Thriving, Satisfied with their job, $\alpha=.95$, averaged in a Positive Emotion index) and the negative emotional status of employees at this company (Under pressure, Stressed, $\alpha=.88$, averaged in a Negative Emotion index), both taken from Benedetti and Chen (2018); d) Whether they would be interested in working for the company (from now on, Working Interest) ; e) Their level of interest for the company's services (Service Interest); f) whether they wanted to forgo a $\$ .10$ bonus to download an ebook offered by the company. All of these questions were asked on a seven-point scale anchored at $1=$ Not at all and $7=$ Very much.

Results

All of the measures below (with the exception of eBook download, which we discuss in further depth in the section dedicated to it) were in line with the estimation hypothesis. That is, overall, the company was penalized in the incomplete information condition (compared to the complete information condition) when quotient was high, and rewarded in the incomplete information condition when quotient was low.

\section{Company Warmth}

A two-way ANOVA with information completeness and quotient as between-subjects factors showed a significant main effect of information completeness, $F(1,598)=9.46, p=$ $.002, \eta^{2}=0.013$, a significant effect of quotient, $F(1,598)=91.09, p<.001, \eta^{2}=0.120$, and a significant two-way interaction between quotient and information completeness, $F(1$, $598)=58.19, p<.001, \eta^{2}=.077$. Post-hoc comparisons (Bonferroni corrected) showed that when quotient was low, there was a significant difference between incomplete information condition, $M=3.72, S D=1.56$ and the complete information condition, $M=2.47, S D=1.49$, $p<.001, d=0.82$. When the quotient was high, this significant difference reversed, such that 
fairness judgments were lower in the incomplete information condition, $M=3.94, S D=1.37$, compared to complete information condition, $M=4.47, S D=1.28, p<.001, d=0.40$.

A moderated mediation analysis using the medmod module for jamovi (The jamovi Project 2019) using the interaction between quotient and information shown as independent variable, employee salary fairness as mediator, and company warmth as dependent variable found a significant moderated mediation index, $a b(\mathrm{SE})=-0.97(0.10), 95 \% \mathrm{CI}[-1.17,-0.78]$.

\section{Company Competence}

A two-way ANOVA with Information shown and Quotient as between-subjects factors showed a significant effect of Information shown, $F(1,598)=10.13, p=.002, \eta^{2}=$ .014 , a significant effect of Quotient, $F(1,598)=61.61, p<.001, \eta^{2}=.086$, and a significant two-way interaction between Quotient and Information shown, $F(1,598)=44.68, p<.001$, $\eta^{2}=.063$. Post-hoc comparisons (Bonferroni corrected) showed that when quotient was low, the company was considered more competent in the incomplete information condition, $M=$ 4.88, $S D=1.43$ compared to the complete information condition, $M=3.75, S D=1.61, p<$ $.001, d=0.74$. When the Quotient was high, this difference reversed, such that company competence was lower in the incomplete information condition, $M=5.01, S D=1.30$, compared to the complete information condition, $M=5.41, S D=1.21, p<.001, d=0.32$.

A moderated mediation analysis using the medmod module for jamovi (The jamovi Project 2019) using the interaction between quotient and information shown as independent variable, employee salary fairness as mediator and company competence as dependent variable found a significant moderated mediation index, ab $(\mathrm{SE})=-0.58(0.08), 95 \%$ CI [$0.73,-0.43]$. 
Positive Workers' Emotion

A two-way ANOVA with Information shown and Quotient as between-subjects factors did not show a significant effect of Information shown, $F(1,598)=4.92, p=.027, \eta^{2}$ $=.006$, a significant effect of Quotient, $F(1,598)=150.69, p<.001, \eta^{2}=.176$, and a significant two-way interaction between quotient and Information, $F(1,598)=101.56, p<$ .001 .

Post-hoc comparisons (Bonferroni corrected) showed that when Quotient was low, there was a significant difference between the condition in the incomplete information condition, $M=3.87, S D=1.58$ and the complete information condition, $M=2.48, S D=1.40$, $p<.001, d=0.93$. When the Quotient was high, this difference reversed, such that in the incomplete information condition employees were considered having less positive emotions, $M=4.12, S D=1.32$, compared to the complete information condition, $M=5.00, S D=1.19$, $p<.001, d=0.70$

A moderated mediation analysis using the medmod module for jamovi (The jamovi Project 2019) using the interaction between quotient and information shown as independent variable, employee salary fairness as mediator and positive emotions as dependent variable found a significant moderated mediation index, $a b(\mathrm{SE})=-1.07(0.11), 95 \% \mathrm{CI}[-1.28,-0.86]$.

\section{Negative Workers' Emotion}

A two-way ANOVA with Information shown and Quotient as between-subjects factors showed a significant effect of Information, $F(1,598)=6.28, p=.013, \eta^{2}=.01$, a significant effect of Quotient, $F(1,598)=10.08, p=.002, \eta^{2}=.016$, and a significant twoway interaction between Quotient and Information shown, $F(1,598)=2.88, p<.001, \eta^{2}=$ .005 
Post-hoc comparisons (Bonferroni corrected) showed that when Quotient was low, there was a significant difference between the incomplete information condition, $M=4.70$, $S D=1.45$, and the complete information condition, $M=5.20, S D=1.60, p=.005, d=0.33$. When the Quotient was high, there was no significant difference between the incomplete information condition, $M=4.53, S D=1.26$, and the complete information condition, $M=$ 4.62, $S D=1.49, p=.547, d=0.07$.

A moderated mediation analysis using the medmod module for jamovi (The jamovi Project 2019) using the interaction between quotient and information shown as independent variable, employee salary fairness as mediator and negative employee emotions as dependent variable found a significant moderated mediation index, ab $(\mathrm{SE})=0.32(0.07), 95 \% \mathrm{CI}[0.18$, $0.45]$.

\section{E-book download}

A logistic regression with quotient and information as categorical factors, and their interactions as independent variables and choice to get the book as dependent variable found no effect of information, $\mathrm{b}(\mathrm{SE})=-.62(.34), \mathrm{z}=-1.88, p=.06$, no effect of quotient, $\mathrm{b}(\mathrm{SE})=$ $-.39(.34), \mathrm{z}=-1.15, p=.251$, and a significant interaction between quotient and information, $\mathrm{b}(\mathrm{SE})=1.011(.474), \mathrm{z}=2.13, p=.033$. When the quotient was low, in the incomplete condition, 24/151 (16\%) of participants chose to forgo the $\$ 0.10$ to download the eBook, while only $17 / 150(11 \%)$ chose to forgo the bonus in the complete condition. When the quotient was high, the opposite happened, as fewer participants $(17 / 150$, or $11 \%)$ chose to forgo the bonus in the incomplete condition compared to the complete condition $(29 / 151$, or $19 \%)$

In retrospect this was misguided as there is no very strong connection between the book and the company, despite the statistically significant interaction. Further, participants 
were asked whether they wanted to forgo a $\$ 0.10$ bonus, which constituted about $20 \%$ of their pay for this HIT to download such a book, which may perhaps have been too high. We maintain that the interaction between information shown and quotient can significantly affect consumer behaviour, as shown in the main paper with the results regarding the interest in trying the company's services. We believe that the e-book download task was not designed appropriately. In study 5, we designed and implemented a better experimental design involving e-book download.

\section{STUDY 5}

Deviations. Participants overestimated median employee pay more in the incomplete information condition $(M=20,156.86, \mathrm{SD}=12,969.97)$ compared to the complete information condition $(M=8,288.87, \mathrm{SD}=11,824.74), t(798)=13.52, p<.001, d=0.96)$. As in the estimation in the main paper, taking the median estimation results in more accurate estimations for the complete information condition $($ Median $=501)$ but not for the incomplete information condition, $($ Median $=21,116)$. 